\title{
Changes in feedstock quality in willow chip piles created in winter from a commercial scale
} harvest

Mark H. Eisenbies (corresponding author) ${ }^{1}$, Timothy A. Volk ${ }^{1}$, Aayushi Patel ${ }^{1}$ 1- State University of New York, College of Environmental Science and Forestry. 1 Forestry Dr., Syracuse, NY 13210, USA Contact information for corresponding author - mheisenb@esf.edu, Ph. 315-470-4850, Fax 315-470-6934

\section{Abstract}

Storage and handling are important facets of biomass logistics because there are associated costs and biomass properties can change significantly as material proceeds through the supply chain. Thus, this aspect of biomass supply systems requires continued study. Shrub willow chips were harvested, and used to create six piles that each contained between 10 and $22 \mathrm{Mg}$ (fresh biomass). Material was monitored for several months in temporary storage to assess changes in biomass quality (moisture, ash and energy content). Internal pile temperatures increased due to biological activity and conditions within a pile quickly differentiated based on location (shell, core, top, and side). Mean moisture content increased from 42 to $47 \%$ (mass fraction) between harvest and delivery of the chips, but ranged between 37 and over $60 \%$ over the next three months depending on pile location with the shell generally drier than the core. Mean ash content increased 1 to 2 percentage points (mass fraction) between harvesting, reloading and delivery to the trial location, but became more variable during storage. Higher heating values (HHV) were stable between 18.6 and $19.0 \mathrm{MJ} \mathrm{kg}^{-1}$ over the six months, but lower heating values (LHV) ranged between 8.6 and $11.7 \mathrm{MJ} \mathrm{kg}^{-1}$ and 
23 mirrored changes in moisture content. There was minimal change in chip quality over two

24 months, but quality became more variable over longer time periods. This period could be

25 extended, and negative effects on chip quality could be mitigated, by improving storage

26 methods, blending different types of chips, or employing pretreatments.

27 Highlights

28 - The ratio of outer shell chips and inner core chips affects overall pile quality

29 - Moisture content was higher in the pile shells compared to their inner core

- Ash content of chips increased most during handling and transportation of material

$31 \quad$ - Results suggest the time and pile configuration should guide sampling intensity

32 - Rapid methods of feedstock assessment may facilitate mitigating variability in future

34 Keywords - Short Rotation Woody Crops; Shrub Willow; Feedstock Quality; Feedstock

35 Variability; Ash Content; Moisture Content

36

\section{Abbreviations}

38 FIFO, first-in first-out; HHV, higher heating value; ISO, International Organization for

39 Standardization; LHV, lower heating value; LIFO, last-in first-out; SRWC, short rotation woody

40 crops 


\section{Changes in feedstock quality in willow chip piles created in winter from a commercial scale}

43 harvest

\section{$44 \quad$ 1. Introduction}

In biomass production systems for bioenergy and bioproducts feedstocks may be

harvested at different times during the year, but logistics and need for year-round demand may

47 require that they be stored for extended periods of time [1-3]. Coming from many potential

48 sources, woody feedstocks have variability in costs, quality, demand, and acceptance [4-6]. This perishable material is often stored in piles or bundles, and with varying levels of protection; thus, there is the potential for feedstock quality to change as it progresses through the supply

51 chain $[5,7,8]$. Kenney et al. [5] especially highlight the importance of characterizing how

52 changes in variability within the supply chain, and range of values for quality metrics, have on

53 end-user processes.

Biomass sourced from shrub willow chips and other short rotation woody crops (SRWC)

55 is a relatively high quality and has consistent mean energy and moisture content at the time of

56 harvest [9] comparable to other biomass sources $[5,10,11]$. Several key attributes of SRWC and

57 other biomass feedstocks (i.e. ash content, moisture content, and energy content) are a

58 persistent concern because of their effect on costs, process efficiency, or materials handling

59 [12-16]. Although there is room for improved flexibility of conversion and handling technologies [14], they are usually optimized for a limited range of variability in feedstock

61 characteristics and do not respond well to large changes in feedstock characteristics, variability, 62 and inconsistency which can create issues for handling systems, and refining or conversion 
processes $[14,17]$. The variability of quality parameters as biomass progresses through the supply chain remains a concern [5].

A load of chipped willow biomass is most homogenous immediately after harvesting [9]. It begins to differentiate as soon as biomass is cut, continuing respiration and introduced microbial processes begin to degrade the material as it is stored in piles that begin to warm $[2,18]$. Microbial activity peaks between 35 and $40^{\circ} \mathrm{C}$. If the chips produced begin to fall under $50 \mathrm{~mm}$ size class they tend to be subject to less drying, lower gas permeability, and increased microbial activity; thus mass loss is greater, and the energy content as received (lower heating value - LHV) [19] are depressed. Depending on how the material is handled after harvest its quality can potentially be improved or degraded and the overall heterogeneity increases unless actions such as some pretreatment activities employed. Key feedstock properties that are subject to change appear to be moisture content, dry matter loss, ash content, and proportion of fines with regards to storage and transport.

Diverse options exist for structuring woody biomass supply systems based on mature industries like pulp and paper, but many challenges remain as the array of woody feedstocks expands, and the products that are made from this material. Information on different logistic components is needed to develop robust supply systems that provide biomass of consistent quality at an affordable price [20-22]. Previous studies have suggested that unprotected chips from short rotation woody crops (SRWC) such as willow can suffer mass loss over time $[2,13]$. Due to concerns for diminished quality, previous recommended storage periods for unprotected chips is two months or less $[3,20]$. 
One challenge with biomass piles is that quality changes at different rates depending on

the location within the pile. The interior of biomass piles develop heterogeneous conditions; thus, feedstock properties will not change evenly within chip piles $[7,8,21]$. Based on previous work, at a basic level, piles differentiate themselves into a shell (generally the upper $50-75 \mathrm{~cm}$ of surface chips on a pile) and core (chips under the shell and within the pile) [8,22-25]; which differ primarily based on temperature and aeration. A finer partitioning of zones might also include a base (chips in contact with the ground), and a cap layer comprised of chips on top of the pile $[26,27]$. A key goal for storage is to minimize temperature to reduce biological activity, and maximize airflow in order to maximize moisture loss. Storage research for chipped woody feedstocks in Europe over the past two decades suggest that the key mitigation practices are to limit the length of storage, or create anaerobic conditions; more recently, progress is being made on facilitating low-cost chip drying in piles [28].

While research concerning the storage and quality of wood chips in piles for large-scale depots or yards from the pulp and paper industry exists [7,23], there is limited information about likely short-term storage of willow biomass in small-scale operations that may involve small piles close to the points of production. Willow varies from pulp quality chips because bark, twigs and sometimes leaves are included in this biomass which can impact both the initial quality of the material and how it responds to storage conditions. There is information that demonstrates how the internal conditions of wood biomass piles differ in other industries, but much less information about how chip quality changes within in dedicated biomass systems. The objective of this study is to evaluate the changes in moisture, ash and energy content of 
105 willow chips that were generated as part of a commercial scale harvest during winter and

106 stored over a period of seven months.

107

108

\section{Material and methods}

\subsection{Source of material}

As part of a commercial-scale harvest [9,29], 21 loads of approximately $150 \mathrm{Mg}$ of fresh willow chips, comprised of the cultivars SV1 (Salix x dasyclados) and S365 (S. caprea), were harvested on Feb 4, 2013 near Groveland, NY $\left(42^{\circ} 42^{\prime} 09^{\prime \prime} \mathrm{N}, 77^{\circ} 44^{\prime} 49^{\prime \prime} \mathrm{W}\right)$. The harvester platform tested was an unmodified New Holland FR9080 harvester, equipped with a New Holland 130FB coppice header blowing chips into tractor-drawn collection vehicles, which transferred chips to waiting trucks for delivery to on-site storage at an unpaved landing within 1 $\mathrm{km}$ of the harvest site. The header cuts whole plants about $10-20 \mathrm{~cm}$ above ground level, and feeds them into the forage harvester using a system of rollers; given the time of year this material only included stems and bark, as leaves had fallen for winter. The length of cut selected by the operator was the largest setting ("33- $\mathrm{mm}$ ") in order to maximize fuel economy and harvesting rate. Weather conditions were cold $\left(-10\right.$ to $\left.0^{\circ} \mathrm{C}\right)$, snowy $(30-50 \mathrm{~cm}$ of snow on open ground), and windy (average $4 \mathrm{~m} \mathrm{~s}^{-1}$; gusts up to $14 \mathrm{~m} \mathrm{~s}^{-1}$ ). Additional site details of the harvesting operations are available in Eisenbies et al.[29].

Based on the source of the willow biomass from dedicated stands and a moisture contents over $35 \%$ (mass fraction) at the time of harvest [9] this material falls under the B1 grade of the ISO standard for graded wood chips [30]. Samples (2-4 kg) of fresh chips were collected from each truck load upon delivery to an on-site storage location. The sample was taken from within the chip mass of each truck load; Briggs et al. [31] showed that further 
127 stratification of the sample from a truck bed was not necessary. Each sample was weighed at

128 the time of collection to the nearest $0.1 \mathrm{~g}$ at the edge of the field on a scale (Mettler-Toledo PG

$1295002-S$ ) in order to obtain the wet weight before the samples could dry in the sun or become

130 wetter due to their proximity to other samples or precipitation. The samples were subsequently

131 returned to the lab within 12 to 24 hours and dried at $60^{\circ} \mathrm{C}$ until they reached a constant

132 weight. Moisture content was determined on a mass basis [32].

133 2.2. Establishment of experimental piles

134 Due to operational delays, the biomass was initially stored for four weeks in a single

135 large pile of comingled loads at the on-site storage. Between March 4, and April 23, 2013, 85

$136 \mathrm{Mg}$ of fresh chips were ultimately transferred into semi-trucks using a bucket loader and

137 delivered in four loads to Tully, NY (N 42.797, W 76.120) where six individual piles of sizes

138 ranging between 10 and $26 \mathrm{Mg}$ (fresh biomass) were established. Two piles were created on

139 March 4, two piles on March 7, one pile on April 11, and one pile on April 23. Three 2-4 kg

140 samples were taken from each load at the time of delivery from the front, middle, and rear

141 section of the pile using a shovel. These samples were weighted and subsequently dried at $60^{\circ} \mathrm{C}$

142 until they reached a constant weight so that moisture content could be determined. Pile

143 dimensions were determined by measuring the long and narrow dimensions of the base, top,

144 pile height, and angle of repose. Pile volume was estimated for pile shapes that represent the

145 shape of the geometric volumes as described in Hardy [33]. The ratio of core volume to total

146 volume was determined by assuming a $45-\mathrm{cm}$ depth to core. Given that the piles did not

147 perfectly match the array of specific geometric shapes described, the closest match was used, 
148 but other relevant shapes were also applied at each pile height in order to obtain a range of 149 possible volumes. Piles were instrumented with temperature loggers (HOBO U12-008, Onset Computer

151 Corp, Cape Cod, MA) that recorded hourly temperature for each probe location. Other studies $152[18,22]$ and recommended sampling protocols under development (ISO draft standards 18135, 153 14780), may partition piles into layers or grids. Only eight probes were available per pile; thus 154 sampling and probe placement was based on a symmetrical scheme that was independent of 155 pile size and simplified routine sampling (Figure 1). Temperature probes were installed ordinally 156 (Top, N, SE, SW) to test for possible aspect differences. Probes were inserted into the pile $1572 / 3$ rds of the height from the base; $45 \mathrm{~cm}$ for a shell sample, and one half the pile heights for 158 the core sample. Probes were precisely installed by inserting a length of steel angle stock into 159 the pile with the peak upward, taping a threaded nut to the probe, guiding probe and wire with 160 a threaded rod along the inside of the angle stock pushing upward to create a void to correct 161 depth, removing the angle, and unscrewing the threaded rod, leaving the probe at the required 162 depth with minimal disturbance. Step ladders were laid on the pile sides for footing and to 163 minimize disturbance while mounting the piles. Chip samples were collected on May 4, July 3, 164 and August 8, 2013 near the probe locations but far enough away so that probes were not 165 disturbed. Shell samples (1-2 kg) were taken using a shovel. Undisturbed core samples were 166 obtained using a custom sampler that was augured to the same depth as the temperature 167 probe for each location. The sampler (similar to a bucket augur) was designed to move into or 168 out of the chip pile by turning the handle clockwise, a door in the side of a sample chamber was 169 subsequently opened by turning the handle counter clockwise and held closed by returning to a 
170 clockwise direction. A minimum of approximately $150 \mathrm{~g}$ was obtained from the core depths

171 using a second coring as required.

172

[INSERT FIGURE 1]

\subsection{Sample collection and processing}

For samples taken from specific locations and depths that were too large to be ground,

177 a stratified subsample for grinding was taken based on sampling guidelines for wood chips

$178 \quad[19,31,34,35]$; up to nine 10 to $15-\mathrm{cm}^{3}$ scoops (three scoops from three layers) were carefully

179 taken from a sample bag and combined. These were subsequently ground in a Wiley mill

180 through a $0.5-\mathrm{mm}$ screen for subsequent lab analyses yielding approximately $120 \mathrm{~cm}^{3}$ of

181 sample. Ash content was determined by a dry-ashing method by placing a crucible with 2-g

182 samples in a cold muffle furnace and raising the temperature slowly up to $550^{\circ} \mathrm{C}$ [36]. Higher

183 heating value was determined using Parr 6200 Oxygen Bomb Calorimeter (Moline, Illinois)

$184[19,37]$ (except for the July sampling date due to the lack of change between May and August).

185 Lower heating value was calculated using moisture content and the formula described in

186 section D2 of Annex D of the ISO standard [19].

187 2.4. Statistical analysis

To assess the quality parameters of chips prior to storage, the 21 individual loads of

189 willow chips sampled at the time of harvest and the four individual loads at the time of delivery

190 were compared using a contrast statement in the MIXED procedure in SAS 9.2 (SAS Inc.; Cary, $191 \mathrm{NC})$. 
Once the willow chip piles were established they became the experimental unit for this

trial. The experiment was a $4 \times 2$ factorial design with four ordinal directions representing solar and wind exposure (Top, N Side, SE Side, and SW Side) and two depths (Shell, <45cm; Core, 1 m). Willow chips were sampled on three different dates (mid-May, early-July, and mid-August) so a repeated measures analysis of a $4 \times 2$ factorial was analyzed using the MIXED procedure

197 (model parameter $=$ block position depth period position*depth position*period depth*period 198 position*depth*period). Thus, the experimental unit was sample location within the pile; the 199 individual piles, which had different sizes and slightly different shapes, were treated as a block 200 effect. Parameter distributions were obtained using the FREQ procedure. In order to approximate the quality of a load of chips once they are reloaded on trucks 202 as compared to the ISO standards for class B wood chips we scaled the pile location means up 203 based on the proportion of shell and core material. This was done by weighting the shell and 204 core samples to the total volume of individual piles based on its physical dimensions and our 205 best estimate of four shapes as described by Hardy [33] (i.e. irregular solid/trapezoidal, 206 paraboloid, half-ellipsoid, half cylinder).

\section{3. Results and Discussion}

3.1. Pile volumes

Pile heights ranged between 1.4 and $2.4 \mathrm{~m}$ tall, 3 to $6 \mathrm{~m}$ on the short axis, and 4 to $10 \mathrm{~m}$

210 on the long axis, with a 40 degree maximum angle of repose (Figure 1). Pile biomass ranged

211 between approximately 8 and $22 \mathrm{Mg}$ (fresh) at the time of delivery from on-site storage to

212 short-term storage; the first four piles were created from split loads (approximately 60:40); the

213 total volume of the delivery trucks was approximately $70 \mathrm{~m}^{3}$. However, the range of volume 
214 estimates based on Hardy [33] for applicable pile shapes differed by up to a factor of 4 for

215 individual piles and thus care should be taken when choosing a pile shape. Despite the wide

216 range of volume estimates, the ratio of core volume to total volume for any assumed shape was

217 more stable; the mean ratio between core and shell chips ranged from 50:50 to 60:40 as the

218 height of the pile increased (Figure 2). In contrast, wood yard chip piles such as those described

219 in Ferrero [18] have larger core volumes that likely constitute more than $85 \%$ of the volume of

220 the pile because of the way material is stacked after being unloaded from trucks. The material

221 in our trial was not manipulated after pile creation.

222

[INSERT FIGURE 2]

224

225

3.2. Overall Pile Compliance

226

There were changes in chip quality associated with on-site storage at the harvest

227 location, and delivery to the short-term storage sites in Tully. The mean ash content of these

228 chips at the time of harvest was $1.9 \%(C V=18 \%)$, which increased to $2.7 \%(C V=29 \%)$ at the time

229 of delivery ( $\mathrm{P}=0.0081$ ) (Table 1). A large proportion (77\%) of the samples from the delivered

230 chips met the ISO ash standard for B1 chips compared to a $100 \%$ pass rate for the freshly

231 harvested chips [9]. Dirt clods were observed in the delivered loads of willow biomass

232 suggesting contamination during the reloading and transportation process. The mean ash

233 content commonly reported for willow ranges between 1.3-2.7\% [38,39], although values for

234 individual samples or sites have been observed to exceed 3\% [9]. 
The mean moisture content of the delivered chips was $47 \%$ (CV=9\%) (mass fraction),

239 which was $5 \%$ percentage points higher than the freshly harvested chips $(P=0.0521)$. However,

240 the maximum moisture content (53\%) had only increased $2 \%$ percentage points compared to

241 the freshly harvested chips. There was no difference in the HHV $\left(18.9 \mathrm{MJ} \mathrm{kg}^{-1}\right)$ between the

242 delivered and freshly harvested chips $(P=0.9445)$, but the coefficients of variation increased

243 slightly from $0.45 \%$ to $2.7 \%$. The LHV mirrored the increase in moisture content. In spite of the

244 fact these loads were delivered at different times, there were no significant differences

245 between ash $(P=0.1008)$, moisture $(P=0.9868)$, HHV $(P=0.4334)$, or $\operatorname{LHV}(P=0.9368)$ for the chips

246 delivered between March and April.

247 3.3. Pile Temperatures

248 Temperature is a surrogate for biological activity in the various zones that develop

249 where properties will change differently due to heating and ventilation $[8,24,27]$. Based on

250 temperature, these piles reached a steady state in early to mid-July. Once all of the chip piles

251 were established, the mean temperature rose throughout the study period reaching a peak

252 temperature just below $50^{\circ} \mathrm{C}$ in the top core, and just below $40^{\circ} \mathrm{C}$ in the sides (Figure 3). Half

253 of the daily temperature exceeded $40^{\circ} \mathrm{C}$ in the top shell and core, $30^{\circ} \mathrm{C}$ in the side core, $25^{\circ} \mathrm{C}$

254 in the side shell (Table 2). Specific moisture and temperature conditions favor different cohorts

255 of fungi and other microorganisms; the resulting conditions may be desirable or undesirable

256 depending on which organisms are active [27]. 
[INSERT TABLE 2]

Passive piles such as these ventilate by taking air in through the sides, and up through

261 the center [26]. The degree of ventilation is a function of chip size and porosity. Air flow and

262 humidity influence the internal temperatures of the pile. There was a slight gradient of $2-5^{\circ} \mathrm{C}$ in

263 mean temperatures between the core and shell at the tops of the piles, and a more substantial

264 gradient of $5-10^{\circ} \mathrm{C}$ on the sides. Overall, there was a $10-15^{\circ} \mathrm{C}$ difference between the tops and

265 sides with considerably more variation amongst the tops from pile to pile; this was possibly due

266 to pile size. Finally, there was very little difference amongst the sides or ordinal direction of the

267 sides (i.e. N, SE, and SW). The temperature gradients appear similar to young, passively aerated 268 compost piles as reported by Fernandes et al. [40].

269 Pile conditions were responsive to changes in ambient air temperature and humidity.

270 Changes in pile temperature lagged behind changes in air temperature in the first half of the

271 study (Figure 3). Temperature also rose and fell with ambient humidity, particularly during the

272 first half of the monitoring period. Lower relative humidity (below $70-80 \%$ ) appears to have

273 facilitated airflow through the pile resulting in heat loss due to evaporative cooling.

[INSERT FIGURE 3]

276

\section{3.4. Moisture Content}

Within the pile, there were significant differences in moisture content between shell

279 and core samples $(P<0.0001)$ and by sampling period $(P<0.0001)$, but not by sun or wind 


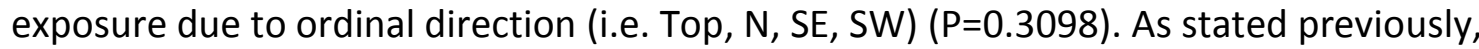
moisture content increased between harvest and delivery to the Tully site by 5 percentage points $(P<0.0001)$. Once the small piles had been established and could sit undisturbed, the moisture content of the core and shell differentiated within weeks (Figure 4). Shell chips quickly lost moisture and dried to levels equal to or less than at the time of harvest. Variability did not increase between harvesting $(\mathrm{CV}=10 \%)$ and pile establishment $(\mathrm{CV}=9 \%)$, and remained low in the shell throughout storage ( $C V=4$ to $16 \%$ ) (Table 1$)$.

[INSERT FIGURE 4] moisture content was different. The peak mean moisture content of the core chips was $54 \%$ (mass fraction) in May and it decreased to $48 \%$ in July and $46 \%$ in August. The moisture content in the core was 7-9 percentage points greater than the shell throughout the study.

Piles were subject to the elements, but not subject to sampling after substantial rainfall events. There was a total of $12.7\left(0.8 \mathrm{~mm} \mathrm{day}^{-1}\right), 272\left(5.5 \mathrm{~mm} \mathrm{day}^{-1}\right)$, and $81.8\left(2.8 \mathrm{~mm} \mathrm{day}{ }^{-1}\right)$ of cumulative rainfall preceding each of the May, July, and August sampling dates respectively.

Each $10 \mathrm{~mm}$ of rainfall has the potential to raise the moisture content of the biomass about 1 percentage point (mass fraction) given the pile footprints and assuming $100 \%$ absorption. While pile heating and ventilation may facilitate moisture loss of chips throughout the pile, aeration and drying are likely fairly heterogeneous at scales relevant to the discrete chips samples locations within the pile. 
By weighting the moisture content of core and shell samples by their proportion of pile

volume based on Figure 2, the moisture content for a reconstituted load can be estimated.

304 There were significant differences in moisture at the measurement locations within the piles

305 between the three periods $(P=0.0164)$ treating each pile as a separate load to be delivered to

306 an end user. Chips piles, as a whole, were significantly drier in July (44\%) and August (42\%),

307 compared to May (49\%). However, the variability of moisture content increased in the core

308 from the time of establishment through the three sampling periods (CV from 10 to 26\%). Such

309 results suggest that care should be taken sampling piles that have been stored for months due

310 to the degree of differentiation that we observed. Specifically, as storage time increases the

311 number of pile subsamples should be increased, and samples taken from shell and core

312 locations. Results also indicate that care should be taken to ensure a fair degree of mixing

313 occurs when chips are reloaded.

\section{$314 \quad$ 3.5. Ash Content in Piles}

With this feedstock, ash is probably the most critical property to manage because once

316 ash content has increased in chips, either from soil contamination or mass loss has occurred

317 due to biological activity, it does not recover without an investment in some pretreatment

318 activity. In this study, ash content increased between initial harvest and delivery by 0.8

319 percentage points, probably due to soil contamination during reloading and transportation as

320 some clods were observed in the material. Once the material reached the study location in Tully

321 for storage there were no significant differences in ash content between the three sample

322 times $(P=0.3526)$. Core samples had a mean ash content across all periods of $4.2 \%$, although

323 not significantly higher than the $3.7 \%$ of the shell $(P=0.1976)$. However, the amount of variation 
324 in the piles increased over time, coefficients of variation increased from $18 \%$ at the time of

325 harvest to a range of $36-83 \%$ during pile monitoring (Figure 5, Table 1). Discrete samples had

326 ash contents as high as $10 \%$ for both shell and core samples, probably the result of soil

327 contamination, but may also be due to mass loss from higher microbial respiration. Regardless,

328 the reported mean ash contents for a variety of bioenergy crops range from below 0.5 to just

329 over $6 \%$ at the time of harvest [10], but the variability of other crops can spike to 15,20 , as high

330 as $40 \%$ or more in some cases [5].

[INSERT FIGURE 5]

There were no significant differences in overall ash content between the three periods

$335(P=0.2026)$; thus ash content did not significantly change during storage. However, the small

336 and statistically insignificant differences in ash might have practical implications on the quality

337 of the material based on ISO standards. As with moisture, the ash content of a composite load

338 can be estimated by weighting the means for the core and shell samples by their proportion of

339 pile volume. Chips piles, as a whole, had mean ash contents below $3.9 \%$ in May and July, versus

$3404.5 \%$ in August. Based on this result, these loads would no longer be compliant with the ISO

341 standard for ash content [30] after 3-6 months of storage. However, the same implication

342 identified with moisture content regarding sampling protocols and ensuring proper mixing of

343 loads may be required during reloading to ensure the aggregate ash content remains within

344 specification. It is clear that for ash content the chain of custody between harvest, storage, and 
345 delivery is an important issue associated with biomass logistics, and can be difficult to track in a 346 disrupted supply chain as with the delayed delivery of these chips.

$347 \quad 3.6$. Energy Content

The HHV remained above $18.6 \mathrm{MJ} \mathrm{kg}^{-1}$ from harvest to delivery and through storage $349(P=0.4253)$ (Figure 6). This result includes a lack of significant differences between the shell and 350 core samples $(P=0.5398)$. However, variability associated with values from discrete locations 351 increased; the coefficients of variation increased from a minimum of $<1 \%$ to a maximum of $4 \%$ 352 (Table 1). The decrease in HHV from 18.9 to $18.6 \mathrm{MJ} \mathrm{kg}^{-1}$ was concurrent with increases in ash 353 content. Increases in HHV for specific observations that contribute to the increased variation 354 are associated with increases in energy density as lower energy density sugars are consumed by 355 microorganisms and high-energy compounds are left behind [41].

356

[INSERT FIGURE 6]

In contrast the mean LHV was significantly different in the core $\left(9.3 \mathrm{MJ} \mathrm{kg}^{-1}\right)$ compared 360 to the shell positions $\left(11.3 \mathrm{MJ} \mathrm{kg}^{-1}\right)(\mathrm{P}<0.0001)$. The changes in variability of LHV (Table 1$)$ are 361 concurrent to the changes in moisture content (Figure 7) $[19,22]$. Thus, as the piles generally 362 dried with time, mean LHV for composite loads significantly improved from 9.6 to $10.8 \mathrm{MJ} \mathrm{kg}^{-1}$ 363 between the May and August sample periods $(P=0.0153)$. 364 


\subsection{Implication}

The longer biomass remains in storage and the more times it is handled, the more variable it becomes. Some of the variation in this experiment was associated with the operational realities of biomass handling and transportation; which highlights the importance of chain of custody to biomass quality. These chips were not handled well. The contractor transporting the chips was not practiced with biomass crops; soil was probably introduced because the unpaved loading area was not smooth or care was not taken to leave a buffer of chips on the ground. It can be a challenge to control the flow of biomass and integrate it into local shipping logistics particularly when demand is uncertain and other commodities are competing for logistic resources. This study, as well as others in the literature, clearly shows the need to establish best practices for storage and handling, the need for monitoring throughout the chain of custody.

The variability of characteristics associated with large scale biomass crops over time and growing seasons has been identified as an important barrier to the large scale commercialization [5]. The influence of shell chips on the overall quality of short term piles may be underappreciated and underrepresented by pile sampling protocols, particularly with regards to the degree that chips in the shell may have better quality. The increasing variation in characteristics within a pile and the composite loads that are created from piles suggests that these issues need to be better understood and managed during operations [5, 45-47]. Developing and deploying tools for rapid quality assessments of feedstock quality (e.g. portable near infrared spectroscopy [42], prompt gamma neutron activation analysis, and x-ray fluorescence [43]) would be beneficial in monitoring quality along the supply chain and for 
389 facilitating the blending of material to ensure that a consistent quality biomass is delivered to 390 end users. Information about not only the means for quality parameters, but also the changes 391 range of values over time, is important because such data will have important repercussions for 392 cost modeling and uncertainty analysis [44,45].

Shrub willow biomass has a stigma for being lower quality feedstocks among some end users; particularly with regards to high ash and moisture, because of the multiple stem nature 395 of the plant and associations with some willow tree species. Freshly harvested willow biomass crops have a consistent quality that is comparable to hardwoods in energy content and most 397 other ways with the possible exception of ash content of debarked chips [46], but is still compliant with ISO standards for class B wood chips $[9,30]$. Moisture content of willow biomass crops at the time of these harvests was lower and more consistent than commonly described $[13,47-50]$. However, these values can change during subsequent handling and storage, particularly in a moist temperate region like the Northeast U.S. Regardless, even when stored in 402 passively aerated, unprotected piles, mean moisture content will apparently fall with time. Keeping ash content within a target standard, such as the ISO limit of three percent, 404 seems to be the primary challenge for crops like willow biomass; without precautions, it only 405 increases as chips are stored and handled. In the case of this study, loads had acceptable 406 properties with the exception of ash content. The issue of high ash content does not preclude 407 acceptance by an end-user who ultimately decides what constitutes acceptable quality. Observably, it is generally best for biomass to head straight to the biorefinery or to 409 some sort of preprocessing depot where improvements to the feedstock quality can occur, or at the minimum some stability achieved. Previous recommendations are that unprotected 
411 storage be limited to two months $[3,20]$; our results support that recommendation with the

412 caveat that piles were created in the spring and monitored into the summer. Piles created

413 during the winter months when outside temperatures are lower may last longer without

414 changes in biomass quality. However, more research is needed to determine how flexible that

415 recommendation may be; best storage practices may require a seasonal component in relation

416 to the length of time material can be stored. The initial quality of the material put into storage

417 will also have an impact [9]. In general piles should be kept as cool and dry as possible, and

418 steps should be taken to facilitate drying; other methods such as compaction are also employed

419 with very large piles [23,51].

420 If biomass from single pass cut and chip harvesting systems is to be stored longer, either

421 protection measures or alternative harvesting methods should be considered. For protection,

422 biomass may be covered by tarps or stored under a fixed cover. Compaction to inhibit air

423 exchange and biological activity is another strategy, but there are risks for spontaneous

424 combustion for chip piles above a certain size [7]. Alternative harvesting methods where SRWC

425 biomass stored as stems, billets, or bales can maintain quality longer compared to chipped

426 biomass $[3,22,52,53]$; however, that introduces additional processing steps and costs; biomass

427 harvested and chipped in a single operation should be cheaper to produce [54].

428

One goal that has been proposed is to create a uniform feedstock supply system to

429 decrease the variability and improve the properties of multiple biomass feedstocks into a single

430 stream [5,54]. Several strategies could be employed to extend the usable lifespan of stored

431 chips. First, mixing or blending feedstocks is an emerging approach. Formulated feedstocks may

432 even improve desirable properties such as energy content [55]. This may entail simple 
strategies where LIFO (last in, first out) and FIFO (first in, first out) inventory management are used to combined older biomass with fresher material [51]. If rapid quality assessments were available, mixing/blending could also be effective in attenuating marginal properties by combining low and high-quality feedstocks at a rate that keeps the overall signal within acceptable ranges. The distinction here between blends, which are carefully formulated, and mixes which are more arbitrary should be noted with regards to some sampling schemes that could be employed.

Successful operational drying of chips is desirable for storage periods greater than two to three months; but research has struggled with how to accomplish this with chipped biomass with out significant costs $[3,8,22,28]$. There are numerous low-cost or no-cost objectives that have been tried; succinctly these include increasing porosity, decreasing fines, and improving ventilation $[20,24,56]$. Using pile configuration that maximize the surface area of the pile is a low-cost possibility, but has not received much attention [7]. There may be a seasonal component to pile configuration. A leaf-on pilot study of willow biomass crops suggested that the cores of piles created in summer were drier than the shells [57]. For biomass where longerterm storage is planned, increased particle sizes (e.g. billets or whole stems) will limit fines which will enhance air flow through the pile and moisture loss, and limit mass loss due to microbial activity; however, such material requires additional processing and additional costs to meet size requirements of end users.

Another possibility is pretreatments that enhance or stabilize material. For example, cleaning loads of ultra fine material $(<0.2 \mathrm{~mm})$ will lower ash content and improve the feedstock quality [58]. Processes such as hot water extraction can serve as a pretreatment. The 
455 extracted chip byproduct has reduced ash and been shown to be advantaged for pulping, wood

456 pellets, and reconstituted wood products, but it accepts wet feedstocks, and the byproducts

457 are a uniform low-ash feedstock and an marketable aqueous solution containing easily

458 fermentable sugars [41]. Preliminary tests with post hot water extraction material suggest that

459 these chips can be stored for a longer period of time with little loss in quality because the

460 hydrophyllic hemicellulose component of the material has been removed.

\section{4. Conclusions}

Willow biomass properties became more variable the more it was handled and the

463 longer it was stored. Properties differentiated as conditions in the shell, core, tops, and sides

464 differentiated. Mean pile temperatures rose consistently over the course of the study and

465 reached a steady state between 25 and 45 degrees $C$ depending on pile location. There was

466 almost a 5 degree difference between core and shell locations, and a 10-15 degree difference

467 between the top and sides. Mean moisture content increased from $42 \%$ to $47 \%$ (mass fraction)

468 between harvest in February and deliveries between March and April. Moisture content

469 decreased over the three-four months after the piles were established such that there was no

470 significant difference in mean between the stored piles and fresh chips, but the material was

471 more variable and differentiated by location. Ash content steadily increased and became more

472 variable through each phase of this study. By the end of the study the mean ash content

473 exceeded the 3\% ISO standard at a load scale, but within the piles some locations were still

474 compliant. One issue was soil contamination after loading. Mean energy content HHV was

475 stable between 18.6 and $19 \mathrm{MJ} \mathrm{kg}^{-1}$, but variability increased over time. Mean LHV ranged 
476 between 8.6 and 11.7 depending on location and period within the pile, and differentiated

477 based on changes in moisture content within the pile.

$478 \quad$ The differentiation in the characteristics of the willow chips in the outer shell and the

479 inner core of the pile has implications for overall quality of the material. Due to the small pile

480 size, the ratio of core to shell volume was between 50:50 and 60:40, which was lower than the

$481 \quad 85: 15$ ratio typical of larger wood yard piles. Managing the size and shape of the pile to

482 manipulate this ratio to maintain chip quality is one approach that should be explored.

Recognizing the widely disparate ways that biomass can be handled and conditions it

484 can be subjected to, this work highlights several needs for future research. In particular,

485 methods for rapidly assessing moisture content and ash content need to be developed and a

486 wider array of storage conditions need to be assessed. Passive, low-cost, methods for

487 maintaining quality need to be assessed (i.e. pile configuration, seasonal storage, chip sizes) to

488 extend the usable lifespan of stored chips. Rapid assessments would provide the means to

489 evaluate these methods as well as methods to mitigate diminished quality due to storage by

490 mixing with high-quality or fresher material. Previous recommendations for unprotected

491 storage are up to two months. If rapid assessment technologies were to become available, the

492 usable lifespan of chips could be extended.

493 Acknowledgements

$494 \quad$ This work was made possible by the funding under award \#EE0001037 from the US

495 Department of Energy Bioenergy Technologies Office, New York State Research and

496 Development Authority (NYSERDA), the Empire State Development Division of Science,

497 Technology and Innovation (NYSTAR) and through the Agriculture and Food Research Initiative 
Agriculture.

500

501

502

503

504

505

506

507

508

509

510

511

512

513

514

515

516

517

518

519

520

521

522

523

524

525

526

527

528

529

530

531

532

533

534

535

536

537

538

539

540

\section{References}

[1] T. Filbakk, O.A. Høibø, J. Dibdiakova, J. Nurmi, Modelling moisture content and dry matter loss during storage of logging residues for energy, Scand. J. For. Res. 26 (3) (2011) 267-277.

[2] C. Idler, V. Scholz, W. Daries, J. Egert, others, Loss reduced storage of short rotation coppice, Res. Pap. IAg Eng LUA LU AG. 37 (1) (2005) 124-134.

[3] P.D. Kofman, R. Spinelli, Storage and handling of willow from short rotation coppice (Internet), Forskiningschentret for Skovog Landskab, Hoersholm, Denmark, 1997 (cited 2016 Jan 8). Available from: http://www.etde.org/etdeweb/servlets/purl/591510-PHLAF7/webviewable/591510.pdf

[4] J. Fargione, J. Hill, D. Tilman, S. Polasky, P. Hawthorne, Land Clearing and the Biofuel Carbon Debt, Science. 319 (5867) (2008) 1235-1238.

[5] K.L. Kenney, W.A. Smith, G.L. Gresham, T.L. Westover, Understanding biomass feedstock variability, Biofuels. 4 (1) (2013) 111-127.

[6] T. Volk, P. Castellano, L.P. Abrahamson, Reducing the cost of willow biomass by improving willow harvest efficiency and reducing harvesting costs, Report 10-23 NYSERDA 9586 (Internet), The New York Sate Energy Research and Development Authority, Albany, NY, 2010 (cited 2016 Jan 8). Available from: http://www.nyserda.ny.gov/-/media/Files/Publications/Research/Biomass-SolarWind/reducing-the-cost-of-willow-biomass.pdf

[7] J. Garstang, A. Weekes, R. Poulter, D. Bartlett, Identification and characterisation of factors affecting losses in the large-scale, non-ventilated bulk storage of wood chips and development of best storage practices, FES B/W2/00716/REP DTI/Pub URN 02/1535 (Internet), First Renewables Ltd., London, 2002 (cited 2016 Jan 8). Available from: http://www.biomassenergycentre.org.uk/pls/portal/docs/PAGE/BEC_TECHNICAL/BEST\%20PRACTI CE/LOSSES\%20IN\%20CHIP\%20STORAGE\%20FILE14947.PDF.

[8] P.D. Kofman, I.M. Thomsen, C. Ohlsson, E. Leer, E. Ravn Schmidt, M. Soerensen, et al., Preservation of forest wood chips, EFP97 - 1383/97-0012 (Internet), Danish Energy Research Programme Biomass, 1999 (cited 2016 Jan 8). Available from: https://www.etde.org/etdeweb/servlets/purl/356239-5z69cU/webviewable/356239.pdf.

[9] M.H. Eisenbies, T.A. Volk, J. Posselius, S. Shi, A. Patel, Quality and Variability of Commercial-Scale Short Rotation Willow Biomass Harvested Using a Single-Pass Cut-and-Chip Forage Harvester, BioEnergy Res. 8 (2) (2014) 546-559.

[10] N. El Bassam, Handboook for bioenergy crops, Earthscan, London, 2010.

[11] D. Karlen, Cellulosic energy cropping systems, Wiley and Sons, West Sussux, UK, 2014.

[12] Q.F. Lee, C.P. Bennington, The effect of particle size distribution on pressure drop through packed beds of cooked wood chips, Can. J. Chem. Eng. 83 (4) (2005) 755-763.

[13] P.D. Kofman, Quality wood chip fuel (Internet), Dan. For. Ext. 2006 (cited 2016 Jan 8). Available from:

http://www.seai.ie/Grants/Renewable_Heat_Deployment_Programme/About_Renewable_Heatin g/Wood_Chip_and_Wood_Pellet_Boilers/Quality_Wood_Chip_Fuel.pdf

[14] C. Dupont, S. Rouge, A. Berthelot, D.D.S. Perez, A. Graffin, F. Labalette, et al., Bioenergy II: Suitability of Wood Chips and Various Biomass Types for Use in Plant of BtL Production by Gasification, Int. J. Chem. React. Eng. 8 (2010) A74. 
[15] V. Archambault-Léger, L.R. Lynd, Fluid mechanics relevant to flow through pretreatment of cellulosic biomass, Bioresour. Technol. 157 (2014) 278-283.

[16] J. Daystar, R. Venditti, R. Gonzalez, H. Jameel, M. Jett, C. Reeb, Impacts of feedstock composition on alcohol yields and greenhouse gas emissions from the NREL thermochemical ethanol conversion process, BioResources. 8 (4) (2013) 5261-5278.

[17] J. Tallaksen, Biomass Gasification: A Comprehensive Demonstration of a Community-Scale Biomass Energy System - Chapter 8: A case study in biomass preprocessing (Internet), University of Minnisota, 2011 (cited 2016 Jan 8). Available from: http://renewables.morris.umn.edu/biomass/documents/USDA_Report/SII_Preprocessing.pdf

[18] F. Ferrero, M. Malow, M. Noll, Temperature and gas evolution during lage scale outside storage of wood chips, Eur. J. Wood Prod. 69 (4) (2011) 587-595.

[19] ISO, Solid Biofules - Fuel specifications and classes - Part 1 General Requirements, ISO/FDIS 172251:2013(E), International Organization for Standardization, Switzerland, 2014.

[20] R. Jirjis, Effects of particle size and pile height on storage and fuel quality of comminuted Salix viminalis, Biomass Bioenergy. 28 (2) (2005) 193-201.

[21] A.H. Bedane, M.T. Afzal, S. Sokhansanj, Simulation of temperature and moisture changes during storage of woody biomass owing to weather variability, Biomass Bioenergy. 35 (7) (2011) 31473151.

[22] M. Barontini, A. Scarfone, R. Spinelli, F. Gallucci, E. Santangelo, A. Acampora, et al., Storage dynamics and fuel quality of poplar chips, Biomass Bioenergy. 62 (2014) 17-25.

[23] W.S. Fuller, Chip pile storage - a review of practices to avoid deterioration and economic losses, Tappi J. 68 (8) (1985) 48-51.

[24] T. Poulsen, Oxygen and carbon dioxide distribution and movement in passively aerated compost piles, Comost Sci. Util. 19 (1) (2011) 25-32.

[25] G. Sampson, J. McBeath, Temperature changes in an initially frozen wood chip pile Research Note PNW-RN-454 (Internet), US Department of Agriculture, Forest Service, , Pacific Northwest Research Station, 1987 (cited 2016 Jan 8). Available from: http://www.fs.fed.us/pnw/pubs/pnw_rn454.pdf

[26] L. Ortiz, A. Tejada, A. Vazquez, G. Veiras, Aprovechamiento de la Biomasa Forestal producida por la Cadena Monte-Industria. Parte III: Producción de elementos densificados (Internet), CIS-Madera, CIS-Madera.com, 2005 (cited 2016 Jan 8). Available from: http://www.unionsagrarias.org/archivos/docs/Aprovechameinto_Biomasa_I.pdf

[27] G. Scott, M. Akhtar, M. Lentz, R. Swaney, Engineering, scale-up, and economic aspects of fungal pretreatment of wood chips, in: Young RA Akhtar M Eds Environ. Friendly Technol. Pulp Pap. Ind., John Wiley and Sons, New York, 1998: pp. 341-383.

[28] J. Schweinle, A. Rodl, P. Borjesson, D. Neary, J. Langeveld, G. Berndes, et al., Assessing the environmental performance of biomass supply chains (Internet). IEA Bioenergy Task 43 Report 2015:TR01, IEA Bioenergy, 2015 (cited 2016 Jan 8). Available from: http://www.fs.fed.us/rm/pubs_journals/2015/rmrs_2015_schweinle_j001.pdf

[29] M.H. Eisenbies, T.A. Volk, J. Posselius, C. Foster, S. Shi, S. Karapetyan, Evaluation of a Single-Pass, Cut and Chip Harvest System on Commercial-Scale, Short-Rotation Shrub Willow Biomass Crops, BioEnergy Res. 7 (4) (2014) 1506-1518.

[30] ISO, Solid Biofules - Fuel specifications and classes - Part 4 Graded wood chips, ISO/FDIS 172254:2013(E), International Organization for Standardization, Switzerland, 2014.

[31] R.D. Briggs, E.H. White, H.W. Yawney, Sampling trailers for estimating moisture content and nutrient content for hardwood chips, North. J. Appl. For. 3 (4) (1986) 156-158.

[32] ASABE, Moisture measurement - ANSI/ASABE Standards S358.2, American Society of Agricultural and Biological Engineers, St Joseph, MI, 2012. 
[33] C. Hardy, Guidelines for estimating volume, biomass, and smoke production for piled slash (Internet). PNW-FTR_364, USDA Forest Service. Pacific Northwest Research Station, Portland, OR, 1996 (cited 2016 Jan 8). Available from: http://www.fs.fed.us/pnw/publications/pnw_gtr364/

[34] SPPB, Wood chips for pulp production (Internet), SCAN-CM 42:06, Scandinavian Pulp, Paper and. Board Testing Committee, Stockhom, Sweden, 2006 (cited 2016 Jan 8). Accessed from: http://www.pfi.no/Documents/Scan_test_methods/C_CM_M/CM_42-06.pdf

[35] TAPPI, Sampling and preparing wood for analysis, T $257 \mathrm{~cm}-02$, Technical Association of the Pulp and Paper Industry, Peachtree Corners, GA, 2002.

[36] R. Westerman, Soil Testing and Plant Analysis, 3rd ed., Soil Science Society of America, Madison, WI, 1990.

[37] ASTM, Standard test method for gross calorific value of coal and coke, ASTM Standard D5865, American Society for Testing and Materials, West Conshohocken, PA, 2013.

[38] T.A. Volk, L.P. Abrahamson, T. Buchholz, J. Caputo, M.H. Eisenbies, Development and deployment of willow biomass crops, in: Cellul. Energy Crop. Syst., Wiley and Sons, NY, 2014: pp. 201-217.

[39] M. Krzyżaniak, M.J. Stolarski, B. Waliszewska, S. Szczukowski, J. Tworkowski, D. Załuski, et al., Willow biomass as feedstock for an integrated multi-product biorefinery, Ind. Crops Prod. 58 (2014) 230-237.

[40] L. Fernandes, W. Zhan, N. Patni, P. Jui, Temperature distribution and variation in passively aerated static compost piles, Bioresour. Technol. 48 (3) (1994) 257-263.

[41] T. Amidon, C. Wood, A. Shupe, Y. Wang, M. Graves, S. Liu, Biorefinery: Conversion of woody biomass to chemicals, energy and materials, J. Biobased Mater. Bioenergy. 2 (2) (2008) 100-120.

[42] S. Tsuchikawa, A review of recent near infrared research for wood and paper, Appl. Spectrosc. Rev. 42 (1) (2007) 43-71.

[43] R. Baranowski, A. Rybak, I. Baranowska, Speciation analysis of elements in soil samples by XRF, Pol. J. Environ. Stud. 11 (5) (2002) 473-482.

[44] J. Caputo, S.B. Balogh, T.A. Volk, L. Johnson, M. Puettmann, B. Lippke, et al., Incorporating Uncertainty into a Life Cycle Assessment (LCA) Model of Short-Rotation Willow Biomass (Salix spp.) Crops, BioEnergy Res. 7 (1) (2013) 48-59.

[45] D.R. Johnson, H.H. Willis, A.E. Curtright, C. Samaras, T. Skone, Incorporating uncertainty analysis into life cycle estimates of greenhouse gas emissions from biomass production, Biomass Bioenergy. 35 (7) (2011) 2619-2626.

[46] S.R. Chandrasekaran, P.K. Hopke, L. Rector, G. Allen, L. Lin, Chemical Composition of Wood Chips and Wood Pellets, Energy Fuels. 26 (8) (2012) 4932-4937.

[47] M.J. Serapiglia, K.D. Cameron, A.J. Stipanovic, L.P. Abrahamson, T.A. Volk, L.B. Smart, Yield and Woody Biomass Traits of Novel Shrub Willow Hybrids at Two Contrasting Sites, BioEnergy Res. 6 (2) (2012) 533-546.

[48] P.J. Tharakan, T.A. Volk, L.P. Abrahamson, E.H. White, Energy feedstock characteristics of willow and hybrid poplar clones at harvest age, Biomass Bioenergy. 25 (6) (2003) 571-580.

[49] J. Schweier, G. Becker, New Holland Forage Harvester's Productivity in Short Rotation Coppice: Evaluation of Field Studies from a German Perspective, Int. J. For. Eng. 23 (2) (2012) 82-88.

[50] M.J. Stolarski, S. Szczukowski, J. Tworkowski, H. Wróblewska, M. Krzyżaniak, Short rotation willow coppice biomass as an industrial and energy feedstock, Ind. Crops Prod. 33 (1) (2011) 217-223.

[51] H. Chaouri, S. Eckhoff, Biomass feedstock storage for quantity and quality preservation, in: Shastri Al Eds Eng. Sci. Biomass Feedstock Prod. Provis., Springer, New York, 2014: pp. 165-194.

[52] R. Jirjis, Storage and drying of wood fuel, Biomass Bioenergy. 9 (1) (1995) 181-190.

[53] M.J. Stolarski, M. Krzyżaniak, S. Szczukowski, J. Tworkowski, J. Grygutis, Changes of willow biomass quality as a renewable energy feedstock harvested with biobaler, J. Elem. 20 (3) (2015) 717-730. 
[54] R. Hess, C. Wright, K.L. Kenney, E.M. Searcy, Uniform-format solid feedstock supply system: A commodity-scale design to produce an infrastructure-compatible bulk solid from lignocellulosic biomass. (Internet), Idaho National Lab, 2009 (cited 2016 Jan 8). Available from: http://inlportal.inl.gov/portal/server.pt/gateway/PTARGS_0_3647_96127_0_0_18/UniformFormatFeedstockSupplySystemDRAFT2. pdf.

[55] N. Yancey, J.S. Tumuluru, C. Wright, Drying, grinding and pelletezation studies on raw and formulated biomass feedstocks for bioenergy applications, J. Biobased Mater. Bioenergy. 7 (5) (2013) 549-558.

[56] Y. Lin, E. Newes, B. Bush, S. Peterson, D. Stright, Biomass scenario model documentation: data and references, National Renewable Energy Laboratory, Department of Energy, Golden, CO, 2013 (cited 2016 Jan 8). Available from: http://www.nrel.gov/docs/fy13osti/57831. pdf.

[57] M.H. Eisenbies, T.A. Volk, L.P. Abrahamson, R. Shuren, B. Stanton, J. Posselius, et al., Development and Deployment of a Short Rotation Woody Crops Harvesting System Based on a Case New Holland Forage Harvester and SRC Woody Crop Header - Final Report, Department of Energy, Washington DC, 2015 (cited 2016 Jan 8). Available from: http://www.esf.edu/willow/documents/HarvestingFinalReport2014.pdf.

[58] S. Jacob, D. Da Silva Perez, C. Dupont, J.-M. Commandré, F. Broust, A. Carriau, et al., Short rotation forestry feedstock: Influence of particle size segregation on biomass properties, Fuel. 111 (2013) $820-828$. 
656 Table 1 Means and coefficients of variation for ash content, moisture content (mass fraction),

657 higher heating value (HHV) and lower Heating Value (LHV) from harvest, delivery, and three

658 sample periods.

\begin{tabular}{|c|c|c|c|c|c|}
\hline Period & Dates & Ash Content & Moisture Content & HHV & LHV \\
\hline & & \multicolumn{2}{|c|}{$\begin{array}{c}------------~ P e r c e n t ~------------- \\
\text { (CV\%) }\end{array}$} & \multicolumn{2}{|c|}{ 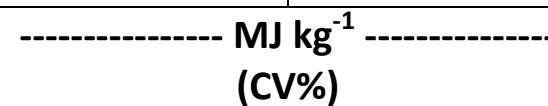 } \\
\hline Harvest & Feb 4 & $\begin{array}{c}1.9 \mathrm{~b}^{\#} \\
(18)\end{array}$ & $\begin{array}{c}42 \\
(10)\end{array}$ & $\begin{array}{l}18.9 \\
(<1)\end{array}$ & $\begin{array}{c}11.3 \\
(6)\end{array}$ \\
\hline Delivery & Mar 4-Apr 23 & $\begin{array}{c}2.7 a^{\#} \\
(29)\end{array}$ & $\begin{array}{l}47 \\
(9)\end{array}$ & $\begin{array}{c}18.9 \\
(3)\end{array}$ & $\begin{array}{l}10.0 \\
(9)\end{array}$ \\
\hline
\end{tabular}

\begin{tabular}{|c|c|c|c|c|c|c|c|c|c|}
\hline & & Shell & Core & Shell & Core & Shell & Core & Shell & Core \\
\hline Period 1 & May 4 & $\begin{array}{c}3.6 \\
(46)\end{array}$ & $\begin{array}{c}4.2 \\
(58)\end{array}$ & $\begin{array}{c}43 b^{*} \\
(16)\end{array}$ & $\begin{array}{c}54 a^{*} \\
(10)\end{array}$ & $\begin{array}{c}18.9 \\
(2)\end{array}$ & $\begin{array}{c}18.8 \\
(4)\end{array}$ & $\begin{array}{c}10.9 \\
a^{*} \\
(12) \\
\end{array}$ & $\begin{array}{c}8.6 b^{*} \\
(13)\end{array}$ \\
\hline Period 2 & July 3 & $\begin{array}{c}3.2 \\
(36)\end{array}$ & $\begin{array}{r}4.0 \\
(45) \\
\end{array}$ & $\begin{array}{c}40 b^{*} \\
(4)\end{array}$ & $\begin{array}{c}48 a^{*} \\
(26)\end{array}$ & & & & \\
\hline Period 3 & August 8 & $\begin{array}{c}4.3 \\
(83)\end{array}$ & $\begin{array}{c}4.9 \\
(53)\end{array}$ & $\begin{array}{c}37 b^{*} \\
(9)\end{array}$ & $\begin{array}{c}46 a^{*} \\
(20)\end{array}$ & $\begin{array}{c}18.7 \\
(4)\end{array}$ & $\begin{array}{c}18.6 \\
(4)\end{array}$ & $\begin{array}{c}11.7 \\
a^{*} \\
(8)\end{array}$ & $\begin{array}{c}10.0 \\
b^{*} \\
(16)\end{array}$ \\
\hline
\end{tabular}


664 Table 2 Percent of daily mean temperature at discrete pile locations at or exceeding given 665 temperature thresholds

666

\begin{tabular}{|c|c|c|c|c|}
\hline Exceeds & \multicolumn{2}{|c|}{ Top of Chip Pile } & \multicolumn{2}{c|}{ Side of Chip Pile } \\
\hline $\begin{array}{c}\text { Temperature } \\
\left({ }^{\circ} \mathbf{C}\right)\end{array}$ & Shell & Core & Core \\
& \multicolumn{3}{|c|}{$\begin{array}{c}\text { percent of mean temperatures } \\
\text { (percent of discrete temperatures) }\end{array}$} \\
\hline $\mathbf{2 0}$ & $100(97)$ & $100(98)$ & $82(82)$ & $97(95)$ \\
\hline $\mathbf{2 5}$ & $100(95)$ & $100(96)$ & $61(58)$ & $78(81)$ \\
\hline $\mathbf{3 0}$ & $98(91)$ & $100(93)$ & $45(33)$ & $56(57)$ \\
\hline $\mathbf{3 5}$ & $92(74)$ & $96(76)$ & $0(10)$ & $39(30)$ \\
\hline $\mathbf{4 0}$ & $51(52)$ & $64(55)$ & $0(0)$ & $0(7)$ \\
\hline $\mathbf{4 5}$ & $26(30)$ & $40(39)$ & & $0(0)$ \\
\hline $\mathbf{5 0}$ & $0(17)$ & $0(20)$ & & \\
\hline $\mathbf{5 5}$ & $0(6)$ & $0(18)$ & & \\
\hline $\mathbf{6 0}$ & $0(0)$ & $0(8)$ & & \\
\hline $\mathbf{6 5}$ & & $0(0)$ & & \\
\hline
\end{tabular}

667

668 


\section{Figure Captions}

Fig. 1 Generic cross section of a pile profile showing sample and temperature probe locations for monitoring the shell and core of the piles at the top and in the side of the pile at three ordinal locations

Fig. 2 Fig. 2 Mean and range of core volume percentages (black line and gray field) for different pile shapes assuming a $45-\mathrm{cm}$ thick shell. Approximate pile heights ranged between 1.4 and 2.4 $\mathrm{m}$, and base dimensions between 3-6 m on the short axes, and 4-10 m on the long axes. Solid points represent observed core percentages for the "best" estimated pile shape. Hollow points are the biomass estimates associated with the right axis

Fig. 3 Temperature of shell/core and top/side locations in six willow chip piles (Above). Vertical error bars indicate the $95 \%$ confidence interval at the beginning and end of the study period. (Below) Mean, daily, ambient air temperature and relative humidity at the pile location

Fig. 4 Distributions of moisture content (mass fraction) for core and shell samples taken from six piles for May 4 (top), July 3 (middle), and August 8 (bottom), 2013. Points with horizontal error bars indicate the mean moisture content of harvested chips and delivered chips and two standard deviations

Fig. 5 Distributions of ash content for core and shell samples taken from six piles for May 4 (top), July 3 (middle), and August 8 (bottom), 2013. Points with horizontal error bars indicate the mean ash content of harvested chips and delivered chips and two standard deviations

Fig. 6 Distributions of gross calorific content dry (higher heating value) for core and shell samples taken from six piles for May 4 (top), and August 8 (bottom), 2013. Points with horizontal error bars indicate the mean HHV of harvested chips and delivered chips and two standard deviations

Fig. 7 Distributions of calorific content as received (lower heating value) for core and shell samples taken from six piles for May 4 (top), and August 8 (bottom), 2013. Points with horizontal error bars indicate the mean LHV of harvested chips and delivered chips and two standard deviations 

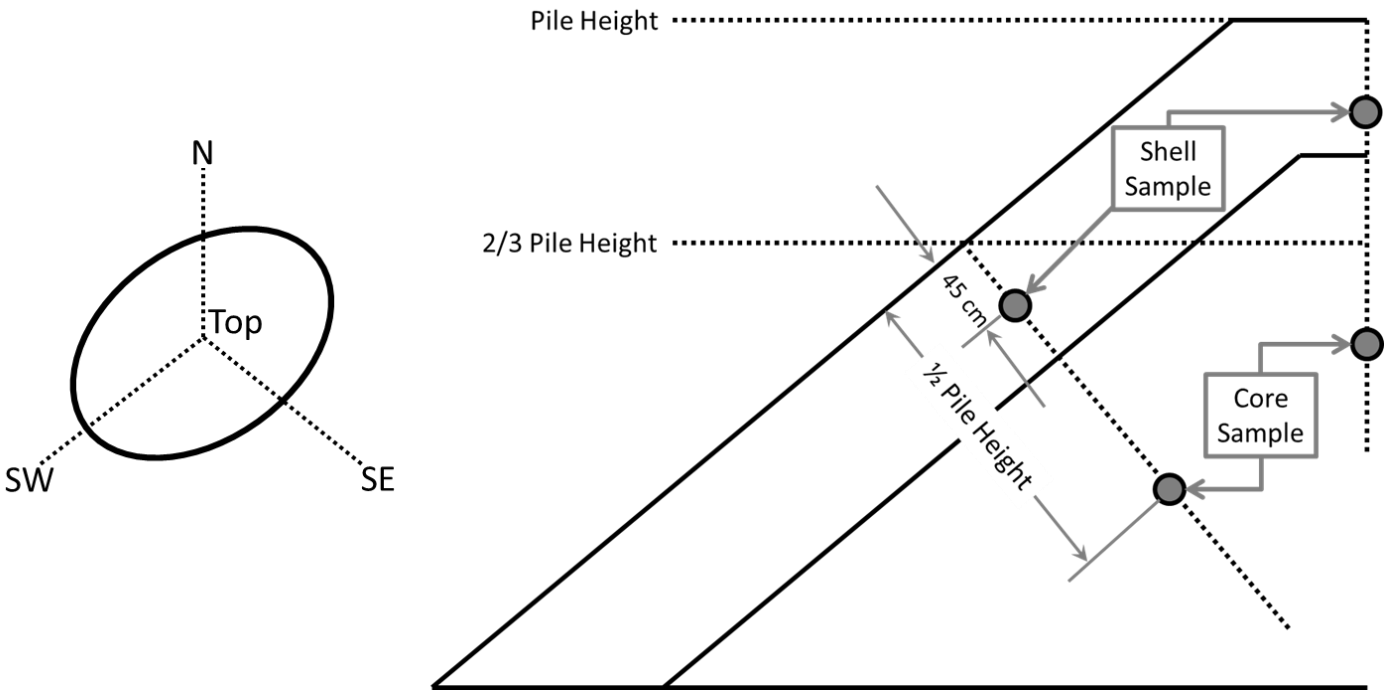

Fig. 1 Generic cross section of a pile profile showing sample and temperature probe locations

709 for monitoring the shell and core of the piles at the top and in the side of the pile at three

710 ordinal locations 


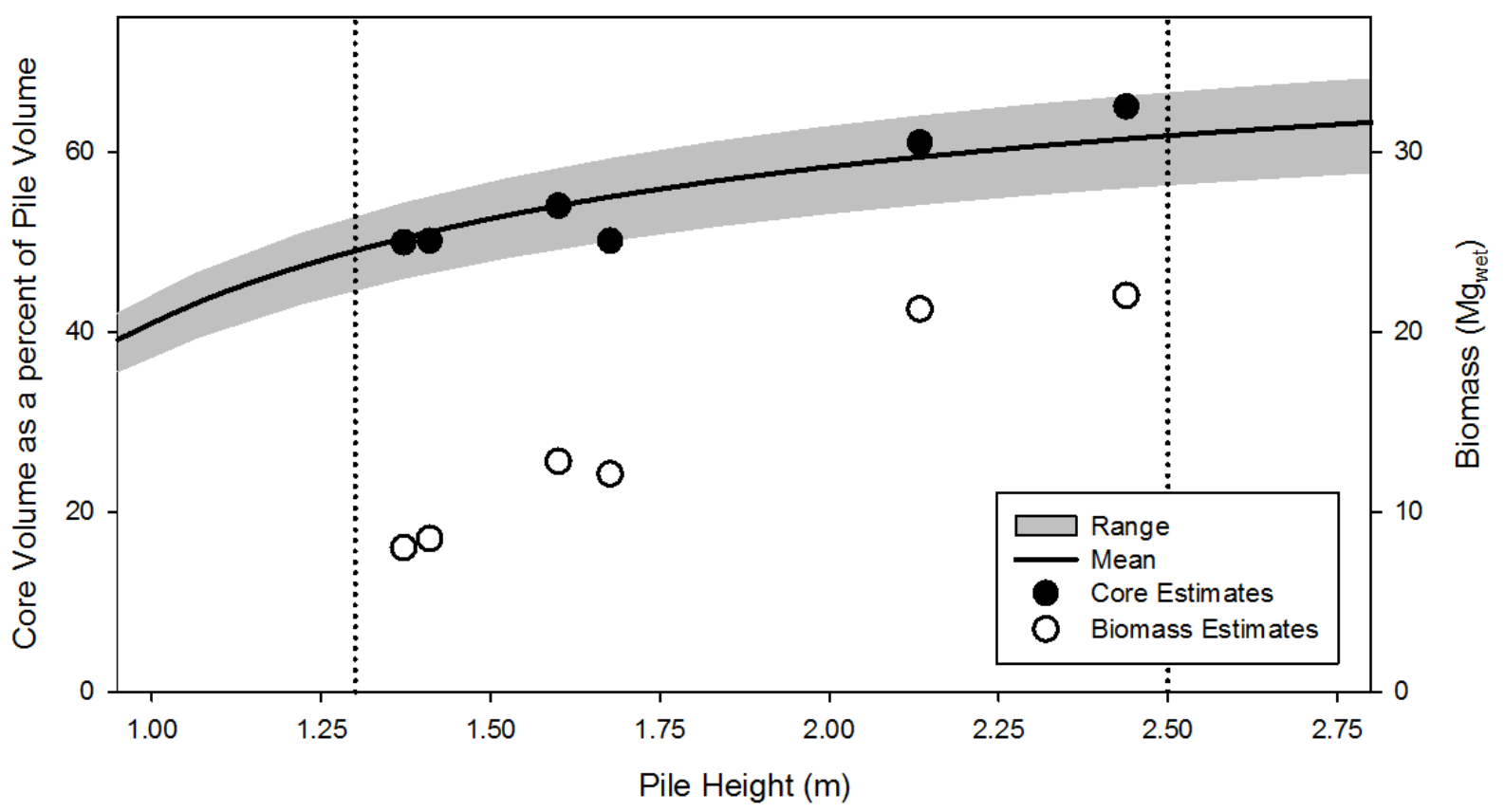

Fig. 2 Mean and range of core volume percentages (black line and gray field) for different pile shapes assuming a $45-\mathrm{cm}$ thick shell. Approximate pile heights ranged between 1.4 and $2.4 \mathrm{~m}$, and base dimensions between 3-6 $\mathrm{m}$ on the short axes, and 4-10 $\mathrm{m}$ on the long axes. Solid points represent observed core percentages for the "best" estimated pile shape. Hollow points are the biomass estimates associated with the right axis 


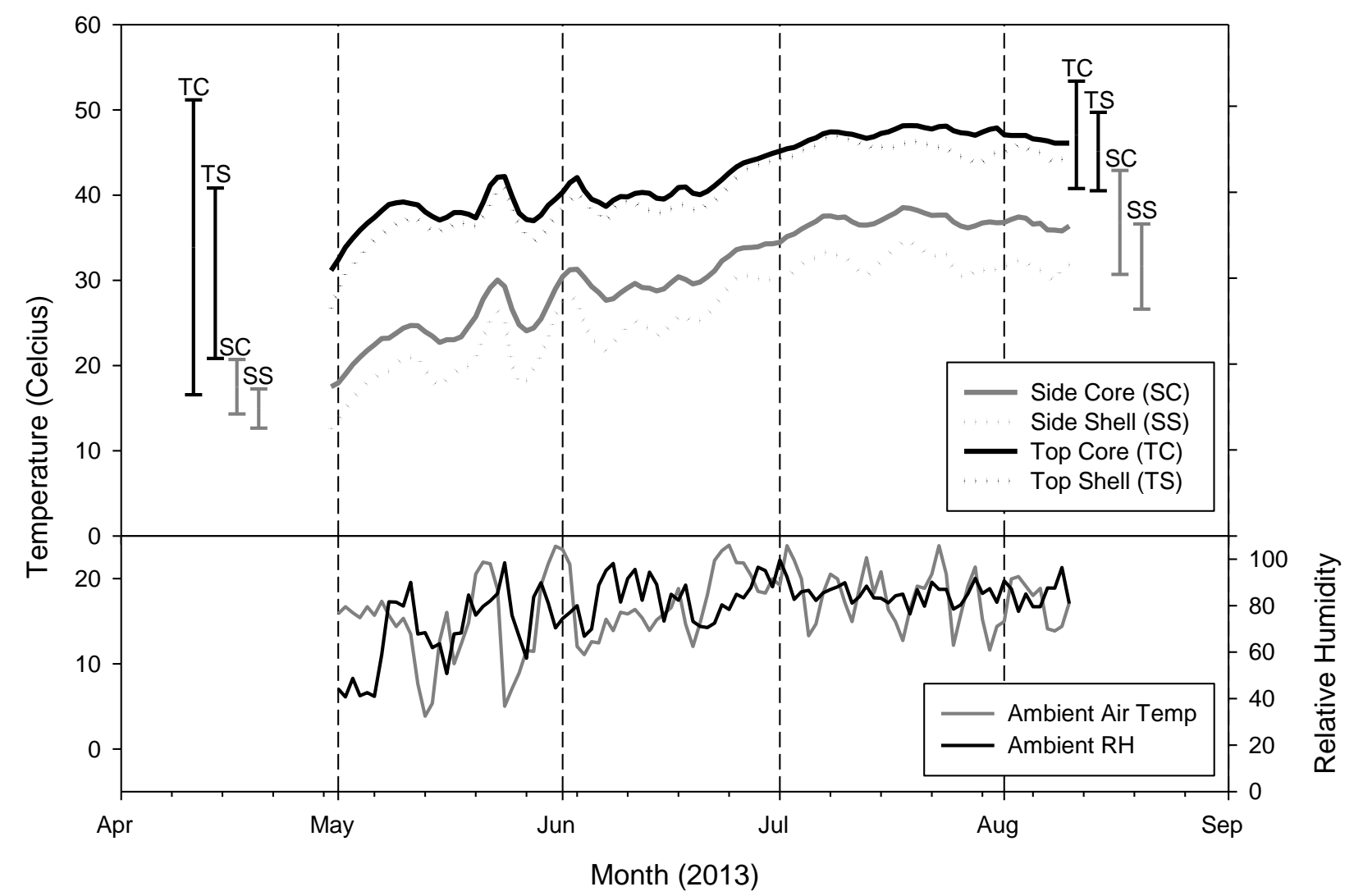

722 Fig. 3 Temperature of shell/core and top/side locations in six willow chip piles (Above). Vertical 723 error bars indicate the 95\% confidence interval at the beginning and end of the study period.

724 (Below) Mean, daily, ambient air temperature and relative humidity at the pile location

725 


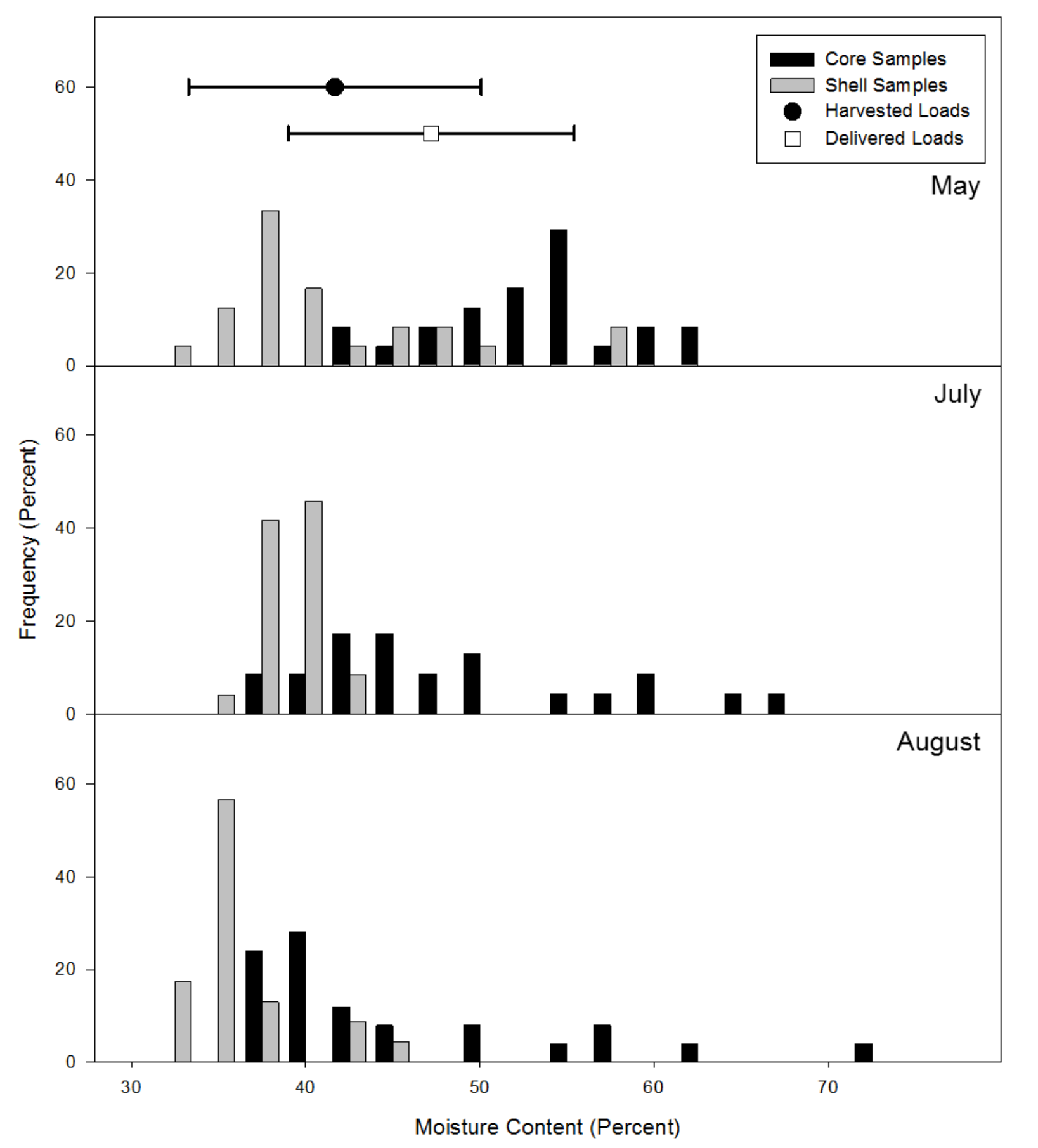

Fig. 4 Distributions of moisture content (mass fraction) for core and shell samples taken from six piles for May 4 (top), July 3 (middle), and August 8 (bottom), 2013. Points with horizontal error bars indicate the mean moisture content of harvested chips and delivered chips and two 732 standard deviations 


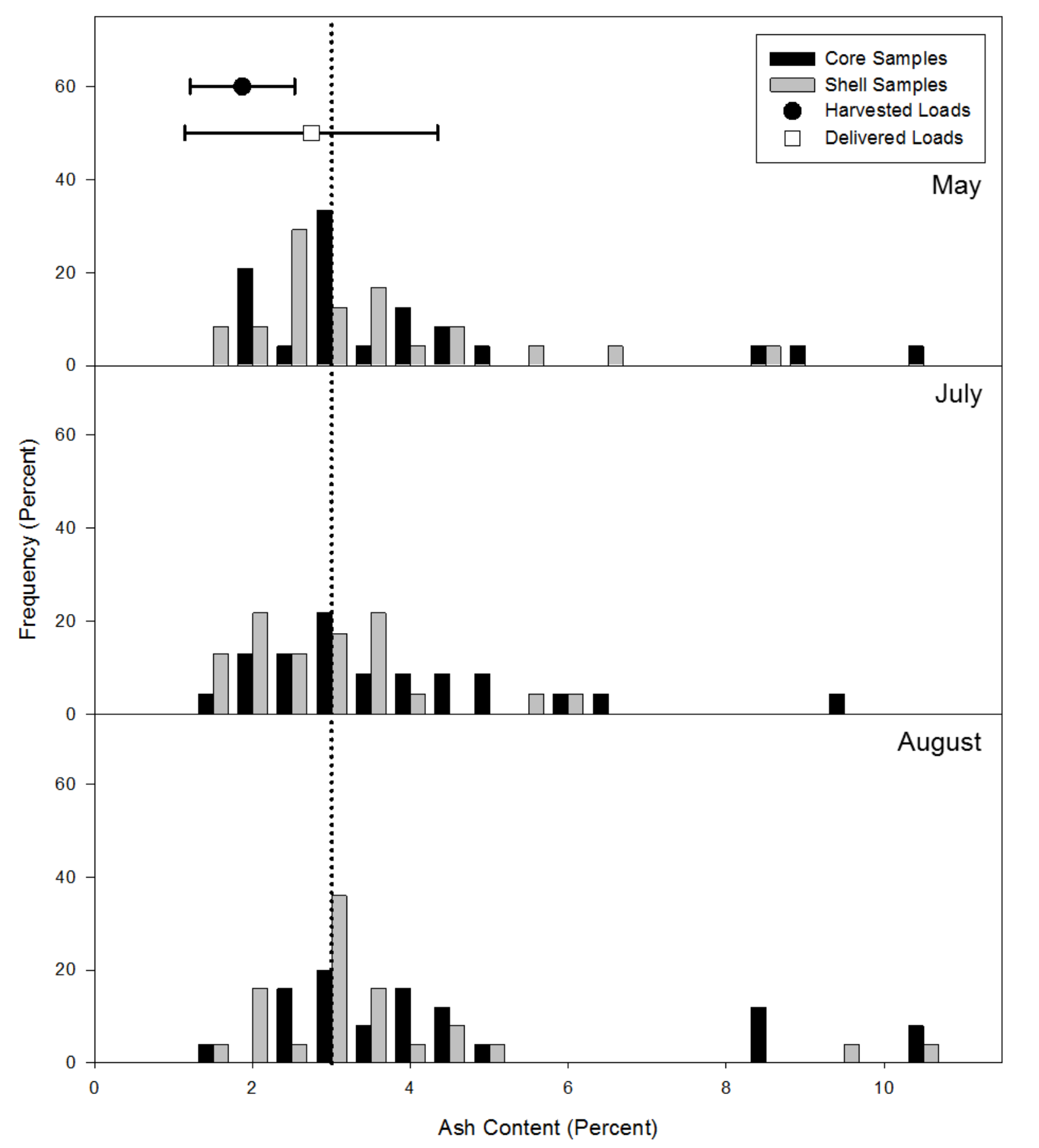

Fig. 5 Distributions of ash content for core and shell samples taken from six piles for May 4 (top), July 3 (middle), and August 8 (bottom), 2013. Points with horizontal error bars indicate the mean ash content of harvested chips and delivered chips and two standard deviations 


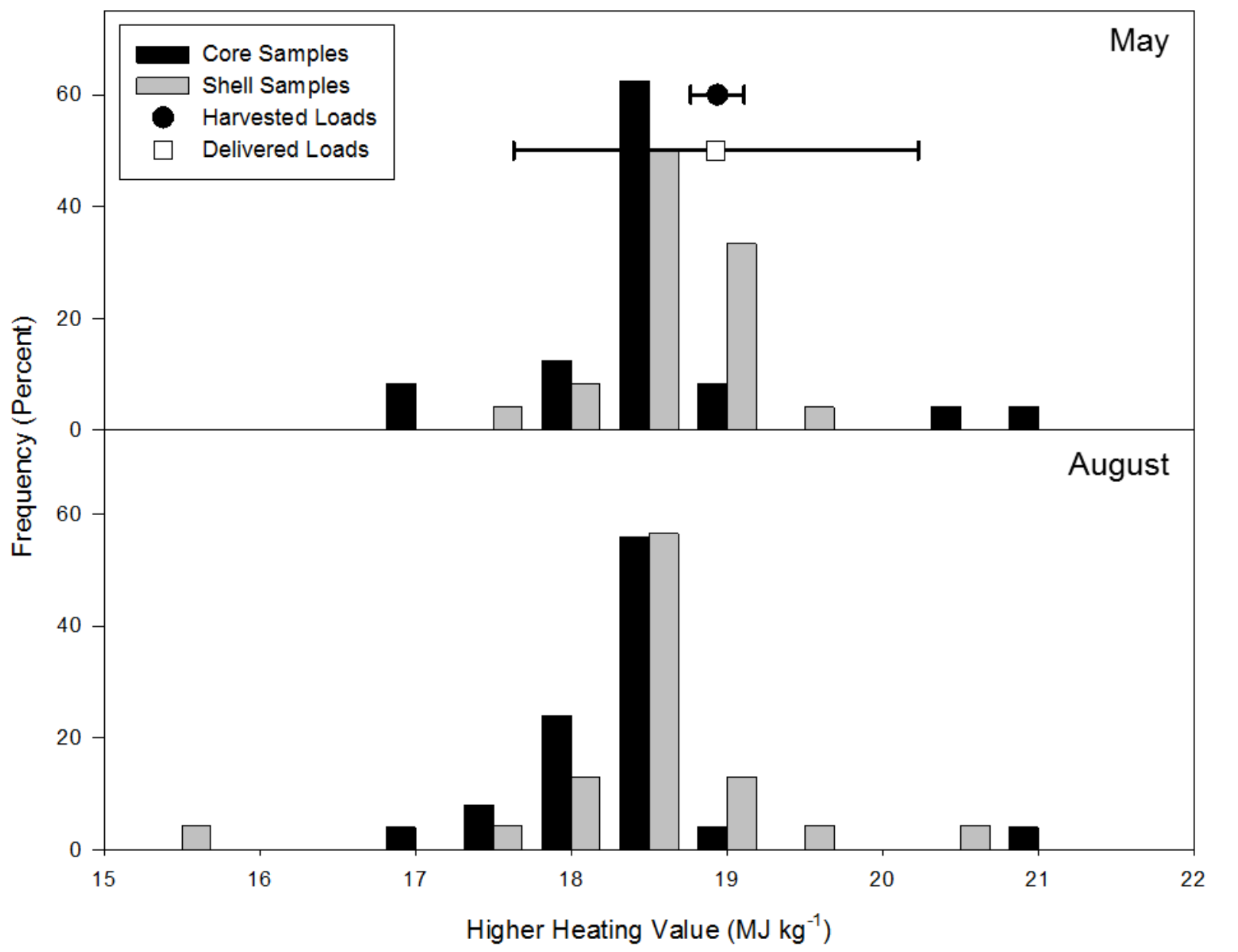

Fig. 6 Distributions of gross calorific content dry (higher heating value) for core and shell samples taken from six piles for May 4 (top), and August 8 (bottom), 2013. Points with horizontal error bars indicate the mean HHV of harvested chips and delivered chips and two standard deviations 


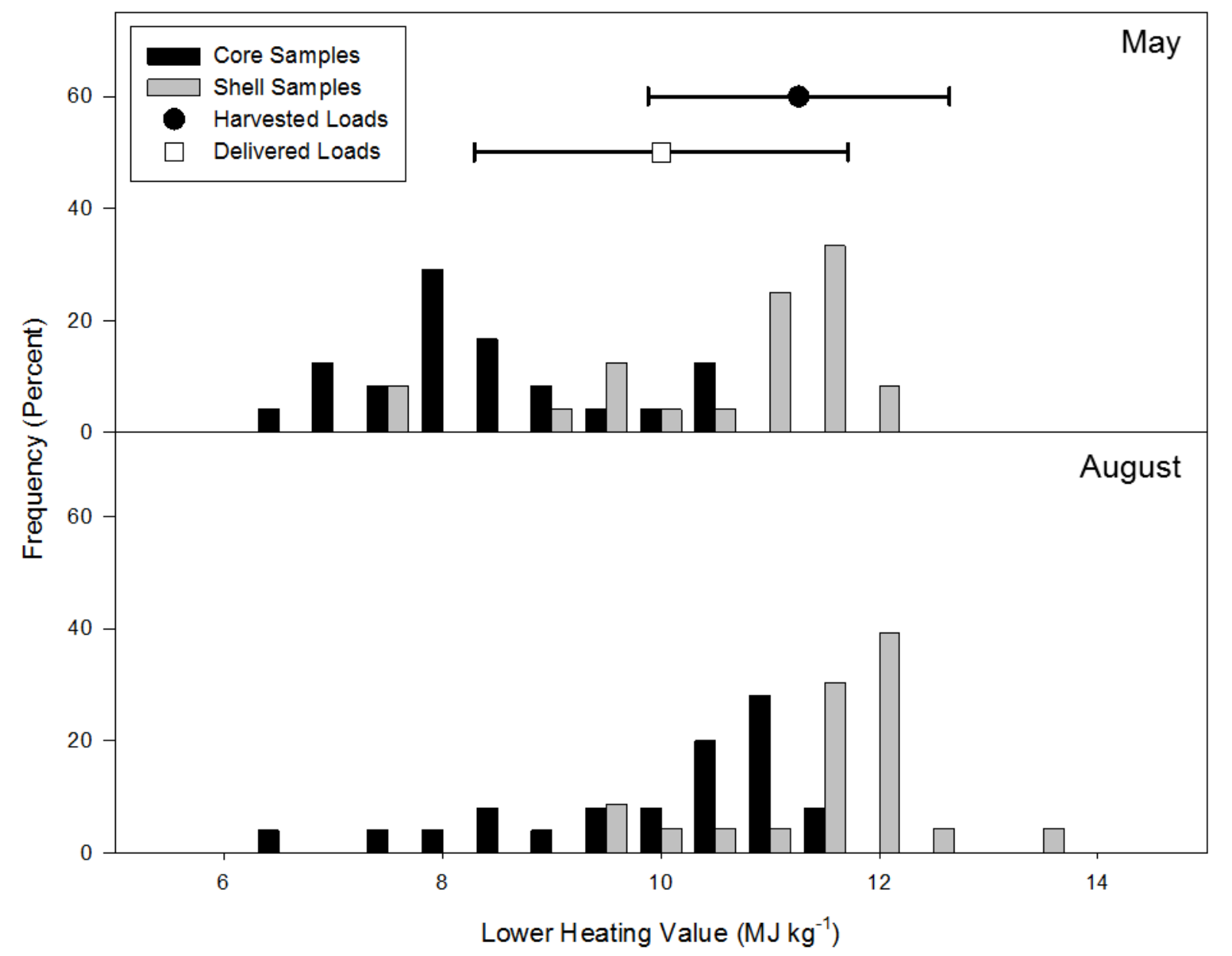

751 Fig. 7 Distributions of calorific content as received (lower heating value) for core and shell

752 samples taken from six piles for May 4 (top), and August 8 (bottom), 2013. Points with 753 horizontal error bars indicate the mean LHV of harvested chips and delivered chips and two 754 standard deviations 